\title{
Lactacidemia in Intrauterine Growth Restricted (IUGR) Pregnancies: Relationship to Clinical Severity, Oxygenation and Placental Weight
}

\author{
ANNA MARIA MARCONI, CINZIA L. PAOLINI, GARY ZERBE, AND FREDERICK C. BATTAGLIA \\ Department of Obstetrics \& Gynecology [A.M.M., C.L.P], DMSD San Paolo, University of Milano, 20142 Milan, Italy; Department of \\ Preventive Medicine \& Biometrics [G.Z.], University of Colorado Health Sciences Center, Denver, CO 80262; Departments of \\ Obstetrics-Gynecology and Pediatrics [F.C.B.], University of Colorado School of Medicine, Aurora, CO 80045
}

\begin{abstract}
The aim of the study was to evaluate the impact of clinical severity and placental weight upon fetal lactacidemia in intrauterine growth restricted (IUGR) pregnancies. Seventy pregnancies complicated by IUGR were compared with 70 normal (appropriate for gestational age, AGA) pregnancies at the time of elective cesarean section. IUGR pregnancies were divided according to clinical severity in three groups: Group 1 had normal fetal heart rate (FHR) and normal pulsatility index of the umbilical artery (PI); Group 2 had normal FHR and abnormal PI; and Group 3 had abnormal FHR and PI. No cases with severe lactacidemia had placental weights $\geq 250$ g. Forty-four fetuses had placental weight $<250$ g: Twenty-four had severe lactacidemia and all were Group 2 and 3, whereas 20 had normal umbilical artery lac (lactate) (and small placentas) regardless of the clinical severity. Gestational age, fetal and placental weights, F/P ratios, uv (umbilical vein) and ua lac and ua oxygen content and $\mathrm{pH}$ were significantly decreased in fetuses with small placentas and high lactate. There was a significant relationship between fetal and placental weight in AGA and IUGR. However, IUGR fetuses with placental weight $\geq 250$ g exhibited an F/P ratio significantly lower than that in AGA fetuses suggesting that IUGR may be due to a reduction of placental function per gram of tissue. (Pediatr Res 59: 570-574, 2006)
\end{abstract}

$\mathrm{L}$ actate represents the end product of anaerobic metabolism of glucose. However, many experimental as well as studies in human pregnancies both in vivo (1-3) and in vitro $(4,5)$ have shown that lactate is produced within the placenta and delivered into both the maternal and umbilical circulation where it serves as source of carbon for fetal growth. This has been clearly demonstrated by studies in pregnant sheep where fetal utilization of lactate at term is three times higher than the umbilical uptake (approximately $4 \mathrm{mg} / \mathrm{kg} / \mathrm{min}$ ) in the welloxygenated fetus (6). The fetal liver is the organ with the highest lactate consumption and liver lactate uptake almost equals umbilical uptake: lactate is then used for oxidation and

Received April 26, 2005; accepted November 21, 2005

Correspondence: Anna Maria Marconi, M.D., Department of Obstetrics and Gynecology, DMSD San Paolo, University of Milano, Via A. di Rudini' 8, 20142 Milano, Italy; e-mail: annamaria.marconi@unimi.it

This work was partially supported by the Association for Study of Malformations (ASM) and National Institutes of Health grant 5 RO1 HD34837-06, Fetal Velocimetry \& Amino Acid Transport in Pregnancy.

A preliminary account of this work was presented at the 2002 Pediatric Academic Societies' Annual Meeting, Baltimore, Maryland.

DOI: 10.1203/01.pdr.0000205477.70391.3e synthesis of fatty acid and glycogen (7). In human pregnancies, fetal lactate concentration is higher than maternal $(2,3)$. Many clinical studies at the time of delivery (i.e. under non-steady stressed conditions) have shown that umbilical venous and arterial lactate concentrations as well as the umbilical venoarterial concentration difference correlate with Apgar scores both at $1^{\prime}$ and $5^{\prime}(8,9)$. In clinical studies performed at the time of spontaneous delivery, lactate concentrations have been shown to represent a much more reliable marker of fetal acidosis compared with $\mathrm{pH}$ measurements $(10,11)$. However, difficulties in sample management have limited its widespread clinical application. Recently the characteristics of L-lactic acid transport across the human placental syncytiotrophoblast have been described $(12,13)$ as has been done for human erythrocytes (14), hepatocytes (15), intestinal brush border membrane $(16,17)$ and skeletal-muscle (18). These studies indicate the presence of an $\mathrm{H}^{+}$dependent carrier which is similar both on the basal membrane (maternal side) (12) and on the brush border membrane (fetal side) (13) of human trophoblast although the difference in sensitivity to phloretine and DIDS suggest that distinct transporters may exist on each side of the trophoblast. The transporters on the basal surface of the trophoblast may provide a driving force for L-lactic acid transport across the basal membrane of the trophoblast into the trophoblast. Since accumulation of Llactic acid can cause acidosis in the fetus, this system may prevent lactate from accumulating in the fetal compartment. No such studies have been performed in placental of intrauterine growth restricted pregnancies. It is clear, though, that under normal conditions, the fetal hepatic uptake of lactate is its major route of disposal.

The present study was performed to explore the relationship between fetal lactate concentration in IUGR fetuses of differ- 
ent clinical severity and to correlate it to fetal oxygenation and placental weight. This study was also prompted by recent reports of decreased fetal hepatic perfusion in IUGR pregnancies (19). Such an occurrence might alter fetal hepatic lactate uptake and increase the risk of fetal acidosis.

\section{MATERIALS AND METHODS}

The study was performed in the Department of Obstetrics and Gynecology of the University of Milan, DMSD San Paolo, Italy. The protocol of the study was approved by the San Paolo Ethical Committee and by the Colorado Multiple Institutional Review Board of the University of Colorado Health Sciences Center. Informed consent was obtained from all patients.

We studied 140 patients at the time of elective cesarean section: Seventy patients had uneventful pregnancies and 70 had pregnancies complicated by intrauterine growth restriction (IUGR). The clinical indication for cesarean section in the normal group was repeat cesarean section or previous uterine surgery ( 38 cases), breech presentation ( 28 cases) and placenta previa (four cases). In IUGR pregnancies the clinical indications to cesarean section are presented in Table 1, according to clinical severity. Gestational age at delivery was calculated by the last menstrual period and confirmed by an ultrasound examination performed within $20 \mathrm{wk}$. Normal growth appropriate for gestational age (AGA) and IUGR were confirmed at birth according to the Italian birth weight-gestational age standard (20). All IUGR fetuses were below the $10^{\text {th }}$ percentile, 41 were below the fifth. No chromosomal abnormalities or fetal malformations were present at birth.

IUGR pregnancies were divided into three groups by clinical severity based on a classification previously proposed (21) and based on the Pulsatility Index of the umbilical artery (PI) measured by Doppler velocimetry and on the fetal heart rate (FHR) recording, obtained within $12 \mathrm{~h}$ from cesarean section. The methodology for PI measurement and FHR analysis have been described elsewhere (21). According to PI and FHR, 23 IUGR pregnancies were classified as Group 1; 20 as Group 2; and 27 as Group 3.

In all cases, cesarean section was performed under general anesthesia after an overnight fast of at least ten hours: none of the patients had entered labor. During surgery the patients were ventilated with nitrous oxide with a concentration of $60 \%$ nitrous oxide and $40 \%$ oxygen. Maternal blood pressure was carefully monitored and no hypotensive episodes were detected. Immediately after fetal extraction, the umbilical cord was doubly clamped and blood was withdrawn from the UA and vein. Maternal blood was collected simultaneously from the radial artery in 67 AGA and 63 IUGR. After delivery, the placenta was collected and weighted trimmed.

Table 2 presents the mean gestational age, fetal and placental weight and fetal/placental weight ratio of AGA pregnancies and IUGR according to clinical severity. It also presents the mean percentage reduction of fetal abdominal circumference, measured by ultrasound within $24 \mathrm{~h}$ from delivery, for each IUGR group calculated using the $50^{\text {th }}$ percentile of AGA fetuses as $100 \%$.

Maternal and fetal blood samples were collected in heparinized 2.5 and 1 $\mathrm{mL}$ syringes respectively, that were immediately sealed and stored on ice. $\mathrm{pH}$, $\mathrm{pO}_{2} \mathrm{mmHg}, \mathrm{pCO}_{2} \mathrm{mmHg}$ were determined on a Radiometer ABL 330 analyzer (Radiometer, Copenhagen DK). Hb concentration $\mathrm{g} / \mathrm{dL}$ and oxygen saturation \% were measured in duplicate on a radiometer OSM-3 oxymeter and oxygen content $\left(\mathrm{O}_{2} \mathrm{C}\right)$ was calculated from these parameters according to the formula:

$\mathrm{O}_{2} \mathrm{C}(\mathrm{mM})=\mathrm{Hb}$ Concentration $\mathrm{g} / \mathrm{dL} \times$ Oxygen Saturation $\times 0.05982$.

Table 1. Clinical indication to cesarean section in IUGR pregnancies according to clinical severity

IUGR 1 IUGR 2 IUGR 3

Fetal indication

Breech presentation $\quad 6 \quad 1$

IUGR

Repeat cesarean

$10 \quad 10$

Non-reassuring CTG

4

10

Maternal indication

$\mathrm{PIH}$

3

6

Maternal + fetal

$\mathrm{PIH}+\mathrm{CTG}$

3

Total

23

20

3

CTG, cardiotocography; PIH, pregnancy induced hypertension.
Lactate concentration was determined in duplicate on a Yellow Spring Analyzer (YS 23L, Yellow Springs, OH). All analyses were completed within 10 min from sampling.

To quantitate fetal net utilization of lactate relative to oxygen uptake, umbilical lactate oxygen quotient (LOQ) was calculated as:

LOQ $=$ Lactate Umbilical Venoarterial Difference $(\mathrm{mM}) \times 3 / \mathrm{O}_{2} \mathrm{C}$ Umbilical Venoarterial Difference (mM).

All the results are presented as mean \pm SEM. The significance of the differences among groups were calculated with the $t$ test for unpaired samples and with the $\chi^{2}$ test after testing for normal distribution of data with an F-test. Regression analyses were carried out by the least squares methods. Differences between slopes were tested using multiple linear regression analysis. $P$-values were considered significant at $p<0.05$.

\section{RESULTS}

Lactate concentration in AGA and IUGR. The mean lactate concentration in the maternal artery and in the umbilical vein and artery are presented in Fig. $1 A$. Figure $1 B$ presents the umbilical venoarterial lactate concentration difference and LOQ and the maternal arterial-umbilical arterial lactate concentration difference in AGA and in the three groups of IUGR pregnancies according to clinical severity. Among these clinical groups, AGA and Group 1 were not significantly different. Group 2 and 3 had progressively more severe lactacidemia. Figure $1 B$ depicts the fact that there were significant differences in the umbilical venoarterial concentration difference for lactate but this was not reflected in the LOQ.

Lactate concentration, fetal and placental weights. Figure 2 presents the relationship between umbilical arterial lactate concentration and placental weight. No cases with severe lactic acidemia (umbilical arterial lactate concentration $>2.18$ $\mathrm{mM}$ ) could be detected for placental weights $\geq 250 \mathrm{~g}$. This placental weight was chosen as the lowest placental weight found in AGA fetuses. In those fetuses with a placental weight $<250 \mathrm{~g}, 24(55 \%)$ had severe lactacidemia and all were Group 2 and 3 fetuses. The remaining 20 fetuses (45\%) had normal arterial lactate concentrations. Surprisingly, all three groups were included in this group with small placentas and normal lactate concentrations regardless of the clinical severity. However, there were no infants with normal velocimetry (AGA and Group 1) who had elevated lactate concentrations, regardless of placental size. Table 3 shows that gestational age, fetal and placental weights, fetal/placental (F/P) ratios, umbilical venous and arterial $\mathrm{O}_{2} \mathrm{C}$ and $\mathrm{pH}$ were all significantly decreased whereas BD was significantly increased in fetuses with small placentas and high lactate. Also, the percentage of absent/reverse end diastolic flow in the UA was significantly increased in these fetuses.

Figure 3 shows the relationship between umbilical arterial lactate concentration and $\mathrm{O}_{2} \mathrm{C}$. The relationship is nonlinear. Below an arterial $\mathrm{O}_{2}$ content of $2 \mathrm{mM}$, only the fetuses of Groups 2 and 3 developed severe lactacidemia.

The relationship between fetal and placental weight in presented in Fig. 4. There is a significant relationship between these two variables in each group (AGA: fetal weight $(\mathrm{FWt})=$ $2615+1.2$ placental weight $(\mathrm{PWt}) ; \mathrm{R}^{2}=0.12 ; p<0.003$, IUGR: $\mathrm{FWt}=407+4.4 \mathrm{PWt} ; \mathrm{R}^{2}=0.62 ; p<0.001$ ). However, it is clear from this figure that IUGR pregnancies represent two different populations. There are fetuses whose 
Table 2. Gestational age at delivery and fetal and placental weights in AGA and IUGR pregnancies according to clinical severity

\begin{tabular}{|c|c|c|c|c|c|c|c|c|c|c|}
\hline & AGA & IUGR 1 & IUGR 2 & IUGR 3 & AGA $v s 1$ & AGA $v s 2$ & AGA vs 3 & 1 vs 2 & 1 vs 3 & $2 v s 3$ \\
\hline Gestational age (weeks) & $38.2 \pm 0.1$ & $37 \pm 0.3$ & $34.2 \pm 0.6$ & $31 \pm 0.5$ & $*$ & $*$ & $*$ & $*$ & $*$ & $*$ \\
\hline Fetal weight (grams) & $3189 \pm 45$ & $2108 \pm 79$ & $1478 \pm 111$ & $953 \pm 82$ & $*$ & $*$ & $*$ & $*$ & $*$ & $*$ \\
\hline Placental weight (grams) & $470 \pm 13$ & $332 \pm 22$ & $248 \pm 25$ & $163 \pm 10$ & $*$ & $*$ & $*$ & 0.02 & $*$ & $*$ \\
\hline$\%$ reduction $\mathrm{AC}$ & & $14.6 \pm 1.1$ & $14.5 \pm 1.6$ & $16.2 \pm 1.2$ & & & & 1 & 0.4 & 0.4 \\
\hline
\end{tabular}

The $\%$ reduction of the abdominal circumference US measurement in IUGR is also shown. AC, abdominal circumference.

$* p<0.001$.
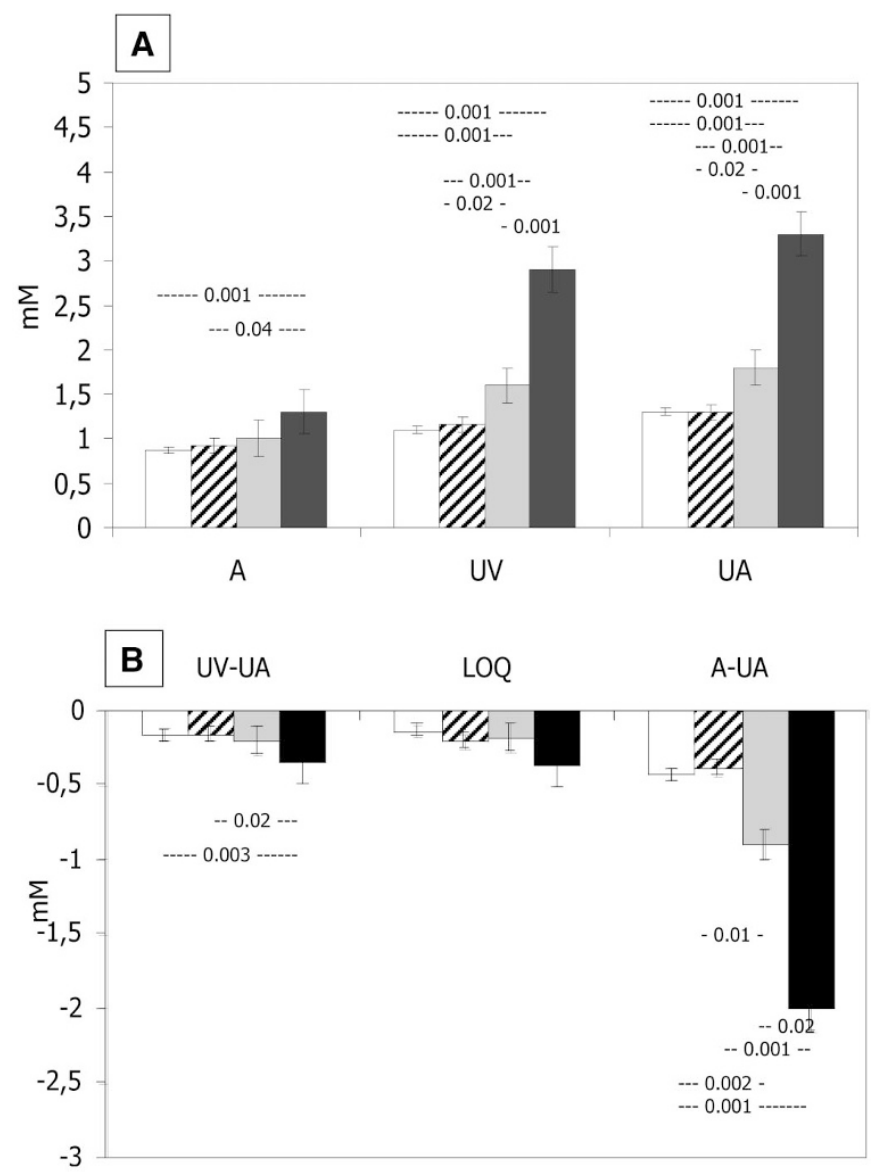

Figure 1. A) Lactate concentration in the maternal artery (AGA $=67$; IUGR Group 1 = 22; IUGR Group $2=17$; IUGR Group $3=23$ ) and umbilical vein and artery (AGA $=70$; IUGR Group $1=23$; IUGR Group $2=20$; IUGR Group $3=27$ ) in AGA pregnancies and IUGR according to clinical severity. $B$ ) Umbilical venoarterial lactate concentration difference (AGA = 70; IUGR Group $1=23$; IUGR Group $2=20$; IUGR Group $3=27$ ), lactate/oxygen quotient $(\mathrm{AGA}=70$; IUGR Group $1=22$; IUGR Group $2=19$; IUGR Group $3=25$ ), and maternal arterial-umbilical arterial concentration difference $($ AGA $=67$; IUGR Group $1=22$; IUGR Group $2=17$; IUGR Group $3=23$ ) in AGA and IUGR pregnancies. AGA: open bars; IUGR Group 1: hatched bars; IUGR Group 2: gray bars; IUGR Group 3: black bars. Values are mean $\pm \mathrm{SE}$.

placental weight is within the normal range $(\geq 250 \mathrm{~g})$ and still are growth-retarded. These cases exhibit an F/P ratio, which is significantly lower than that in AGA fetuses ( $5.5 \pm 0.3$ versus $7.1 \pm 0.2 ; p<0.001)$ suggesting that intrauterine growth restriction may be due to placental insufficiency; i.e. placental function per gram of tissue is reduced.

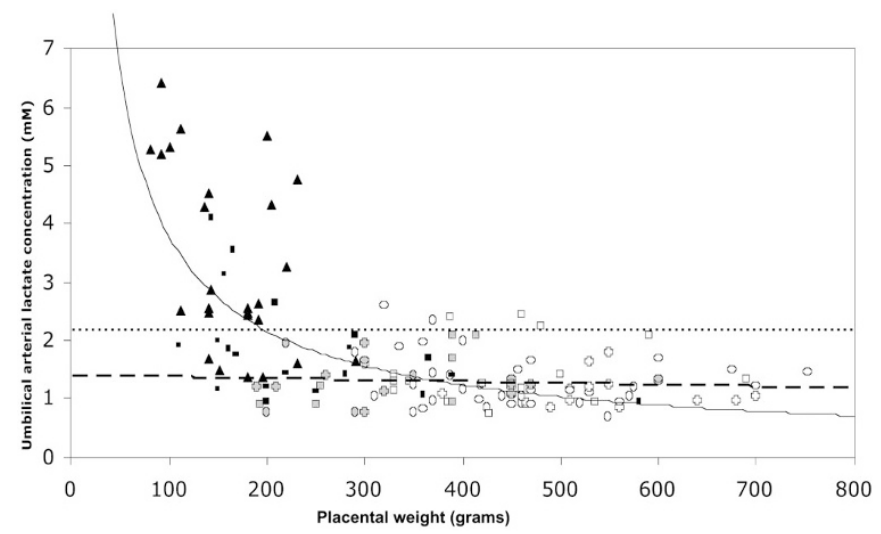

Figure 2. Relationship between umbilical arterial lactate concentration and placental weight in AGA pregnancies and IUGR according to clinical severity. The linear regression line (hatched) was calculated for AGA and IUGR Group 1 pooled together, since the regression analysis of each separately were not different $(p=0.8)$. UA lac $(\mathrm{mM})=1.4-0.0003 \mathrm{PWt}($ grams $) ; \mathrm{R}^{2}=0.006$; $p=0.5$. On the contrary the data of IUGR Group 2 and 3 fitted a curvilinear model: UA lac $(\mathrm{mM})=154.5 \mathrm{PWt}(\mathrm{grams})^{-0.8} \mathrm{R}^{2}=0.37 ; p<0.01$. The horizontal dotted line represents the value for umbilical arterial lactate concentration $(2.18 \mathrm{mM})$ that is $2 \mathrm{SD}$ above the mean in AGA. AGA $(n=$ 70): open circles; IUGR Group $1(n=23)$ : grey circles; IUGR Group $2(n=$ 20) black squares; IUGR Group $3(n=27)$ : black triangles.

\section{DISCUSSION}

The aim of this study was to determine the relationships among three variables; severity of growth restriction, placental weight and feto/placental lactate metabolism. Previously, many studies have analyzed fetal lactate concentrations in different clinical situations. These studies have shown that lactate concentrations present a reliable assessment of fetal acidosis with a good correlation with neonatal outcome $(8,9,10)$.

This study has demonstrated significant differences in feto/ placental lactate metabolism between normal and IUGR pregnancies. For fetuses with birth weights $<10^{\circ}$ centile, both maternal and fetal lactate concentrations are increased compared with normal pregnancies. This is not surprising since IUGR is a clinical situation at highest risk of intrauterine hypoxia and/or acidosis. However, we have previously reported that velocimetry measurements of the UA coupled with the analysis of the fetal heart rate can distinguish groups of different clinical severity among IUGR fetuses. This is valid not only for parameters commonly related to fetal well being (21) (i.e. fetal oxygenation and acid base balance) but also for glucose (22) and amino acid metabolism (23). These studies, as well as the present study, have demonstrated that, in IUGR fetuses with normal PI and normal FHR there are no significant differences when compared with normally grown fetuses 
Table 3. Gestational age at delivery, fetal and placental weights and oxygenation and acid base balance values (mean \pm SE) in IUGR whose placental weight was $<250$ grams and umbilical arterial lactate concentration above or below 2SD of AGA

\begin{tabular}{|c|c|c|c|}
\hline & UA lactate $<2 \mathrm{SD}$ & UA lactate $>2 \mathrm{SD}$ & $P$-value \\
\hline Gestational age (weeks) & $33.7 \pm 0.7$ & $30.8 \pm 0.6$ & 0.002 \\
\hline Fetal weight (grams) & $1388 \pm 105$ & $959 \pm 96$ & 0.004 \\
\hline Placental weight (grams) & $188.4 \pm 8.3$ & $155 \pm 9$ & 0.01 \\
\hline ARED Flow & $7 / 20$ & $17 / 24$ & 0.03 \\
\hline $\mathrm{UV} \mathrm{O}_{2} \mathrm{C}(\mathrm{mM})$ & $5.1 \pm 0.3$ & $4 \pm 0.2$ & 0.001 \\
\hline $\mathrm{UA} \mathrm{O}_{2} \mathrm{C}(\mathrm{mM})$ & $1.7 \pm 0.2$ & $1.2 \pm 0.1$ & 0.04 \\
\hline $\mathrm{UA} \mathrm{pH}$ & $7.274 \pm 0.008$ & $7.202 \pm 0.014$ & 0.001 \\
\hline UV BD & $-2 \pm 0.3$ & $-5.2 \pm 0.7$ & 0.001 \\
\hline UA BD & $-2 \pm 0.4$ & $-5.9 \pm 0.7$ & 0.001 \\
\hline UV lactate concentration (mM) & $1.27 \pm 0.08$ & $3.4 \pm 0.2$ & 0.001 \\
\hline UA lactate concentration (mM) & $1.4 \pm 0.09$ & $3.8 \pm 0.3$ & 0.001 \\
\hline UV-UA lactate concentration difference (mM) & $-0.13 \pm 0.05$ & $-0.42 \pm 0.06$ & 0.001 \\
\hline
\end{tabular}

ARED flow, absent/reverse end diastolic flow.

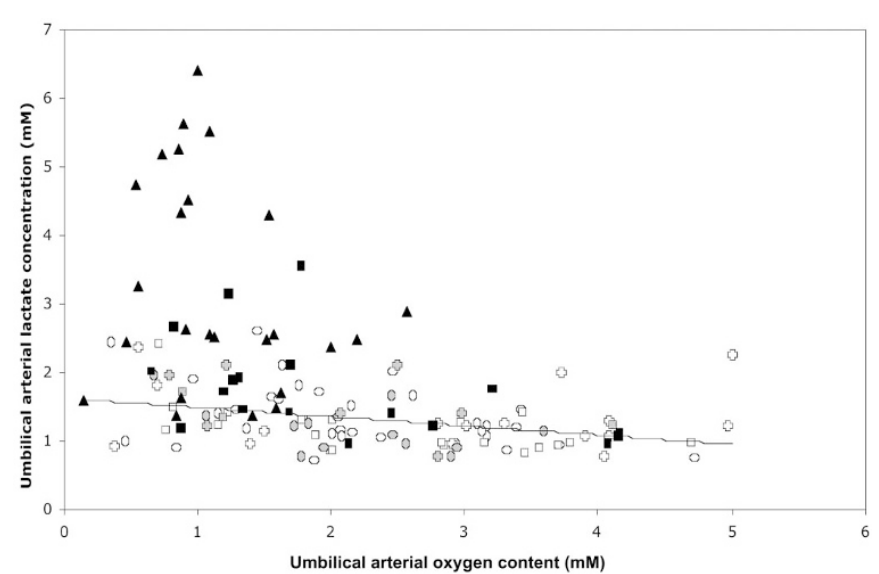

Figure 3. Relationship between umbilical arterial lactate concentration and $\mathrm{O}_{2} \mathrm{C}$ in AGA pregnancies and IUGR according to clinical severity. As in Fig. 2 , the regression line was calculated for AGA and IUGR of Group 1 pooled together since the two were not different $(p=0.8)$. UA lac $(\mathrm{mM})=1.62-0.13$ UA cont $(\mathrm{mM}) ; \mathrm{R}^{2}=0.12 ; p<0.001$. AGA $(n=70)$ : open circles; IUGR Group $1(n=22)$ : grey circles; IUGR Group $2(n=19)$ black squares; IUGR Group $3(n=25)$ : black triangles.

except for a reduced leucine enrichment ratio (23). In contrast, IUGR fetuses of Group 2 and 3 have a higher incidence of hypoxia, acidosis, and hypoglycemia.

The present study also demonstrates that fetal/placental lactate metabolism is altered in these pregnancies according to the clinical severity as defined previously and that these changes in lactate metabolism correlate with placental weight.

Gestational age remains a confounding variable in all such studies. Often the most severe cases, (Group 3), are the earliest in onset and these are the cases with the highest incidence of lactacidemia. Figure 2 brings out the importance of the placental weight in clarifying which Group 2 and 3 fetuses are severely acidotic. IUGR cases with normal placental weights maintain lactate concentrations within the normal limits. We have previously shown that lactate concentration does not change during gestation (21) which permits comparison of fetuses at different gestational ages.

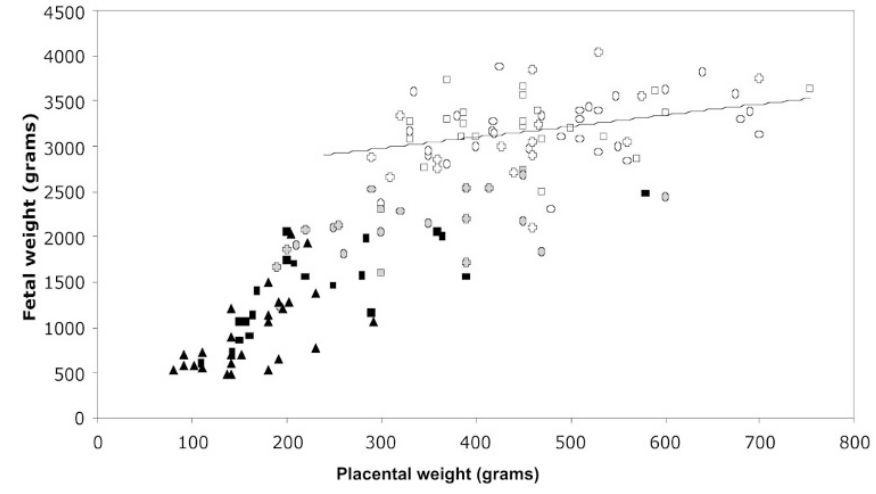

Figure 4. Relationship between fetal and placental weight in AGA pregnancies and IUGR according to clinical severity. The regression line for AGA is presented: Fetal weight $($ grams $)=2615+1.2$ placental weight $($ grams $) ; \mathrm{R}^{2}$ $=0.12 ; p<0.003$. AGA $(n=70)$ : open circles; IUGR Group $1(n=23)$ : grey circles; IUGR Group $2(n=20)$ black squares; IUGR Group $3(n=27)$; black triangles.

The present study confirms our previous observations (2) of acid base balance in IUGR with a much larger data set and adds placental weight to the analysis, namely that lactate is significantly increased in IUGR fetuses with abnormal PI. A previous study had clearly established that there is a significant reduction in umbilical blood flow in Group 2 and 3 IUGR pregnancies. This is true even when umbilical blood flow is expressed per kg fetal weight (19). Thus, it is not surprising that the present study demonstrates a significantly reduced $\mathrm{O}_{2}$ content in the fetal arterial circulation in Group 2 and 3 IUGR pregnancies as well as a significant lactacidemia.

Finally, it is important to note in Fig. 3 that $\sim 50 \%$ of Group 1 pregnancies had reduced umbilical arterial $\mathrm{O}_{2}$ content at delivery. This should be interpreted cautiously since previous studies from our group $(21,24)$ and several other groups $(25,26)$ have shown that this is not the case when the samples are collected at cordocentesis, reflecting normal steady state conditions. The present data were collected at cesarean section where the stress of anesthesia and surgery may impact umbilical blood flow and fetal oxygenation. 
The key role of the placental size in sorting out these IUGR infants with the highest risk of lactic acid is shown in Fig. 4. The functional role of the placenta in IUGR pregnancies is still under investigation. Many studies have shown that IUGR placentas are smaller than AGA placentas $(27,28)$. Based on this observation, many investigators have hypothesized that asymmetrical IUGR is determined by placental hypoplasia (reduction of placental mass). However, the present study highlights IUGR fetuses with normal placental weights that are still growth-retarded. The F/P ratio is decreased either in IUGR with placental weight $<250 \mathrm{~g}$ who are lactacidemic or in IUGR fetuses with normal placental weight who are not lactacidemic: we interpret this observation as being the result of a reduction in placental mass which is inadequate to meet fetal needs throughout gestation in the first group of fetuses (low fetal weight, low placental weight) whereas in the second group with normal placental weight (and low fetal weight) it is likely that the functional capacity of the placenta (placental function per gram of tissue) may be impaired.

Acknowledgments. This work was partially supported by the Association for Study of Malformations (ASM) and National Institutes of Health grant 5 RO1 HD34837-06, Fetal Velocimetry \& Amino Acid Transport in Pregnancy. A preliminary account of this work was presented at the 2002 Pediatric Academic Societies' Annual Meeting, Baltimore, Maryland.

\section{REFERENCES}

1. Burd LI, Jones MD Jr., Simmons, MA Makowski EL, Meschia G, Battaglia FC 1975 Placental production and foetal utilisation of lactate and pyruvate. Nature 254:710 711

2. Marconi AM, Cetin I, Ferrazzi E, Ferrari MM, Pardi G, Battaglia FC 1990 Lactate metabolism in normal and growth-retarded human fetuses. Pediatr Res 28:652-656

3. Stembera ZK, Hodr J 1966 The relationship between the blood levels of glucose, lactic acid and pyruvic acid in the mother and in both umbilical vessels of the healthy fetus. Biol Neonat 10:227-238

4. Carstensen MH, Leichtweiss HP, Schroder H 1983 Lactate carriers in artificially perfused human term placenta. Placenta 4:165-174

5. Holzman IR, Philipps AF, Battaglia FC 1979 Glucose metabolism, lactate and ammonia production by the human placenta in vitro. Pediatr Res 13:117-120

6. Sparks JW, Hay WW, Bonds D, Meschia G, Battaglia FC 1982 Simultaneous measurements of lactate turnover rate and umbilical lactate uptake in the fetal lamb. J Clin Invest 70:179-192

7. Gleason CA, Rudolph CD, Bristow J, Itskovitz J, Rudolph AM 1985 Lactate uptake by a fetal sheep liver. J Develop Physiol 7:177-183
8. Suidan JS, Young BK 1984 Outcome of fetuses with lactic acidemia. Am J Obstet Gynecol 150:33-37

9. Suidan JS, Wasserman JF, Young BK 1984 Placental contribution to lactate production by the human fetoplacental unit. Am J Perinatol 1:306-309

10. Kruger K, Hallberg B, Blennow M, Kublickas M, Westgren M 1999 Predictive value of fetal scalp blood lactate concentration and $\mathrm{pH}$ as markers of neurologic disability. Am J Obstet Gynecol 181:1072-1078

11. Nordstrom L, Ingemarsson I, Westgren M 1996 Fetal monitoring with lactate. Baillieres Clin Obstet Gynaecol 10:225-242

12. Inuyama M, Ushigome F, Emoto A, Koyabu N, Satoh S, Tsukimori K, Nakano H, Ohtani H, Sawada Y 2002 Characteristics of L-lactic acid transport in basal membrane vesicles of human placental syncytiotrophoblast. Am J Physiol Cell Physiol 283:822-830

13. Balkovetz DF, Leibach FH, Mahesh VB, Ganapathy V 1988 A proton gradient is the driving force for uphill transport of lactate in human placental brush-border membrane vescicles. J Biol Chem 263:13823-13830

14. Deuticke B, Beyer E, Forst B 1982 Discrimination of three parallel pathways of lactate transport in the human erythrocyte membrane by inhibitors and kinetic properties. Biochim Biophys Acta 684:96-110

15. Poole RC, Halestrap AP 1993 Transport of lactate and other monocarboxylates across mammalian plasma membranes. Am J Physiol 264:C761-C782

16. Tiruppathi C, Balkovetz DF, Ganapathy V, Miyamoto Y, Leibach FH 1988 A proton gradient, not a sodium gradient, is the driving force for active transport of lactate in rabbit intestinal brush-border membrane vesicles. Biochem J 256:219-223

17. Ritzhaupt A, Wood IS, Ellis A, Hosie KB, Shirazi-Beechey SP 1998 Identification and characterization of a monocarboxylate transporter (MCT1) in pig and human colon: its potential to transport L-lactate as well as butyrate. J Physiol 513:719-732

18. Wilson MC, Jackson VN, Heddle C, Price NT, Pilegaard H, Juel C, Bonen A, Montgomery I, Hutter OF, Halestrap AP 1998 Lactic acid efflux from white skeletal muscle is catalyzed by the monocarboxylate transporter isoform MCT3. J Biol Chem 273:15920-15926

19. Bellotti M, Pennati G, De Gasperi C, Bozzo M, Battaglia FC, Ferrazzi E 2004 Simultaneous measurements of umbilical venous, fetal hepatic, and ductus venosus blood flow in growth-restricted human fetuses. Am J Obstet Gynecol 190:13471358

20. Parazzini F, Cortinovis I, Bortolus R, Fedele L 1991 Standard di peso alla nascita in Italia. Ann Ost Ginecol Med Perinat 112I:203-246

21. Pardi G, Marconi AM, Cetin I, Lanfranchi A, Bozzetti P, Ferrazzi E, Buscaglia M, Battaglia FC 1993 Diagnostic value of blood sampling in fetuses with growth retardation. N Engl J Med 328:692-696

22. Marconi AM, Paolini C, Buscaglia M, Battaglia FC, Pardi G 1996 The impact of gestational age and fetal growth on the maternal-fetal glucose concentrations difference. Obstet Gynecol 87:937-942

23. Marconi AM, Paolini CL, Stramare L, Cetin I, Fennessey PV, Pardi G, Battaglia FC 1999 Steady state maternal-fetal leucine enrichments in normal and intrauterine growth-restricted pregnancies. Pediatr Res 46:114-119

24. Pardi G, Buscaglia M, Ferrazzi E, Bozzetti P, Marconi AM, Cetin I, Battaglia FC, Makowski EL 1987 Cord sampling for the evaluation of oxygenation and acid-base balance in growth-retarded human fetuses. Am J Obstet Gynecol 157:1221-1228

25. Nicolaides KH, Economides DL, Soothill PW 1989 Blood gases, pH and lactate in appropriate-and small-for-gestational-age fetuses. Am J Obstet Gynecol 161:9961001

26. Weiner CP 1990 The relationship between the umbilical artery systolic/diastolic ratio and umbilical blood gas measurements in specimens obtained by cordocentesis Am J Obstet Gynecol 162:1198-202

27. Molteni RA, Stys SJ, Battaglia FC 1978 Relationship of fetal and placental weight in human beings: fetal/placental weight ratios at various gestational ages and birth weight distributions. J Reprod Med 21:327-334

28. Heinonen S, Taipale P, Saarikoski S 2001 Weights of placentae from small-forgestational age infants revisited. Placenta 22:399-404 